\title{
Self-healing of fatigue crack in epoxy materials with epoxy/mercaptan system
}

\author{
Y. C. Yuan ${ }^{1,3}$, M. Z. Rong 1 , M. Q. Zhang2*, G. C. Yang1, J. Q. Zhao ${ }^{3}$ \\ ${ }^{1}$ Key Laboratory for Polymeric Composite and Functional Materials of Ministry of Education, DSAPM Lab, School of \\ Chemistry and Chemical Engineering, Sun Yat-sen University, Guangzhou 510275, P. R. China \\ ${ }^{2}$ Materials Science Institute, Sun Yat-sen (Zhongshan) University, Guangzhou 510275, P. R. China \\ ${ }^{3}$ College of Materials Science and Engineering, South China University of Technology, Guangzhou 510640, P. R. China
}

Received 9 July 2010; accepted in revised form 17 September 2010

\begin{abstract}
Successful retardation or arrest of fatigue crack is observed in self-healing epoxy composite containing dual encapsulated healant, i.e. two types of microcapsules that respectively include epoxy prepolymer and mercaptan/tertiary amine hardener. Fast curing of the released healing agent from the broken capsules leads to rapid development of its bonding strength and fracture toughness at room temperature. It is found that the effects of microcapsules induced-toughening, hydrodynamic pressure crack tip shielding, polymeric wedge and adhesive bonding of the healing agent are responsible for the extension of fatigue life. Depending on the applied stress intensity range, $\Delta K_{\mathrm{I}}$, and the competition between polymerization kinetics of the healing agent and crack growth rate, the above mechanisms exert different influences on crack retardation. The results might serve as a reference for further improving the performance of the healant system under fatigue circumstances.
\end{abstract}

Keywords: smart polymers, fracture and fatigue, self-healing, epoxy

\section{Introduction}

Fatigue and fatigue failure are critical for polymeric materials used in structural applications. Most polymeric materials suffer from poor fatigue resistance and would fail at stress levels much lower than the critical stress intensity, $K_{\text {IC. }}$ Therefore, imparting self-healing capability to polymers and polymer composites [1-9] should be an effective way to solve the problem. It is hoped that the fatigue cracks can be autonomously eliminated soon after their emergence.

So far, only a few papers of healing of fatigue failure have been reported in the literature for polymeric materials. Daniel and Kim [10] investigated fatigue damage in asphalt by evaluating the changes in the stiffness gain under high temperature during the rest period. Zako and Takano [11] studied crack healing in notched epoxy composite specimens using tensile fatigue tests. The stiffness could almost be fully recovered by application of heat to trigger flow and polymerization of embedded particles of B-staged epoxy resin. Nevertheless, the influence of healing process on neither crack growth rate nor absolute fatigue life was considered in their works [5].

Brown et al. [4] firstly established a protocol to extend fatigue life of epoxy using dicyclopentadiene (DCPD). Viscous flow of DCPD in the crack plane retarded crack growth, and its polymerized version further acted as a wedge at the crack tip for artificial crack closure. On the basis of this pilot research, they prepared self-healing epoxy with embedded DCPD-loaded microcapsules and particulate Grubbs' catalyst, which was capable of 
responding to propagating fatigue cracks by autonomic processes that led to higher endurance limit and life extension, or even complete arrest of cracking [5-8], in addition to the ability to repair the cracks generated by monotonic fracture [9]. The degree of fatigue life extension was found to be dependent on the relative magnitude of mechanical kinetics of crack propagation and chemical kinetics of healing.

In our previous work [12], the epoxy/mercaptan/ tertiary amine healing system proved to be able to suppress and rehabilitate fatigue crack in epoxy materials via manual infiltration. Effect of adhesive curing process on fatigue crack propagation was studied in detail. As a continuation of our project, the present paper is focused on self-healing of fatigue crack in epoxy composites containing dual encapsulated healant, i.e. two types of microcapsules that respectively include epoxy prepolymer as the polymerizable component and mercaptan/tertiary amine catalyst as the hardener. The knowledge might provide deeper understanding of the healant for future application.

\section{Experimental}

\subsection{Materials and specimen preparation}

The encapsulated healing agent, poly(melamineformaldehyde)-walled capsules containing epoxy and its hardener, was made according to the methods described elsewhere [13]. The epoxy-loaded microcapsules hold a 1:1 weight ratio mixture of diglycidyl ether of bisphenol A (EPON 828, Hexion
Specialty Chemicals, Columbus, USA) and diglycidyl ether of resorcin (J-80, Wuxi Resin Factory of Bluestar New Chemical Materials Co., Ltd., Jiangsu, China), while the hardener-loaded microcapsules include pentaerythritol tetrakis (3-mercaptopropionate) (PMP, Fluka Chemie AG, Buchs, Switzerland) and 2,4,6-tris(dimethylaminomethyl) phenol (DMP-30, Shanghai Medical Group Reagent Co., Shanghai, China). For comparative study, polythiol-loaded microcapsules containing only PMP without amine catalyst were also synthesized. Table 1 lists the specifications of the capsules.

Unfilled epoxy specimens in the form of tapered double cantilever beam (TDCB, with groove length of $55 \mathrm{~mm}[14,15])$ were cast from the mixture of 100 parts EPON 828 and 12.5 parts diethylenetriamine (DETA, Shanghai Medical Group Reagent Co., Shanghai, China), while the self-healing epoxy specimens of the same configuration were prepared by uniformly mixing $10 \mathrm{wt} \%$ epoxy-loaded microcapsules and $10 \mathrm{wt} \%$ hardener-loaded microcapsules with the aforesaid mixture of EPON 828 and DETA. Control specimens were fabricated with $10 \mathrm{wt} \%$ epoxy-loaded microcapsules and $10 \mathrm{wt} \%$ polythiol-loaded microcapsules (that exclude tertiary amine catalyst) to inhibit the healability of the healing agent, while maintaining other characteristics of the capsules. The compounds were degassed, poured into a closed silicone rubber mold and cured for $24 \mathrm{~h}$ at room temperature, followed by $48 \mathrm{~h}$ at $40^{\circ} \mathrm{C}$. Table 2 shows the material properties.

Table 1. Description of the microcapsules

\begin{tabular}{|l|c|c|c|c|}
\hline \multicolumn{1}{|c|}{ Names } & $\begin{array}{c}\text { Average diameter } \\
{[\boldsymbol{\mu m}]}\end{array}$ & $\begin{array}{c}\text { Density } \\
{\left[\mathbf{g} / \mathbf{c m}^{3}\right]}\end{array}$ & \multicolumn{2}{c|}{ Core substance } \\
\cline { 3 - 5 } Epoxy-loaded microcapsules & 104.3 & 1.24 & $\begin{array}{c}\text { EPON 828 } \\
\text { Ingredient }\end{array}$ & $\begin{array}{c}48.7 \\
\text { Content [wt\%] }\end{array}$ \\
\hline Hardener-loaded microcapsules & 102.1 & 1.23 & PMP & $\begin{array}{l}81.2 \\
15.7\end{array}$ \\
\hline Polythiol-loaded microcapsules & 101.9 & 1.25 & PMP-30 & 97.1 \\
\hline
\end{tabular}

Table 2. Properties of the specimens of cured epoxy and its composites

\begin{tabular}{|l|c|c|c|}
\hline \multicolumn{1}{|c|}{ Properties } & Neat epoxy specimens & Control specimens $^{*}$ & Self-healing specimens $^{* * *}$ \\
\hline Density $\left[\mathrm{g} / \mathrm{cm}^{3}\right]$ & 1.172 & 1.182 & 1.186 \\
\hline$K_{\mathrm{IC}}\left[\mathrm{MPa} \cdot \mathrm{m}^{1 / 2}\right]$ & $0.587 \pm 0.016$ & $0.692 \pm 0.023$ & $0.695 \pm 0.038$ \\
\hline Young's modulus $[\mathrm{GPa}]$ & $3.7 \pm 0.2$ & $3.2 \pm 0.3$ & $3.2 \pm 0.1$ \\
\hline Paris power law exponent, $n^{* * *}$ & 7.12 & 4.20 & - \\
\hline Paris power law constant, $C_{0}{ }^{* * *}$ & 0.11 & $4.3 \cdot 10^{-4}$ & - \\
\hline
\end{tabular}

${ }^{*}$ The control specimens contain $10 \mathrm{wt} \%$ epoxy-loaded microcapsules and $10 \mathrm{wt} \%$ polythiol-loaded microcapsules (excluding tertiary amine catalyst)

${ }^{* *}$ The self-healing specimens contain $10 \mathrm{wt} \%$ epoxy-loaded microcapsules and $10 \mathrm{wt} \%$ hardener-loaded microcapsules

${ }^{* * *} n$ and $C_{0}$ were obtained according to equation (3) reported in ref. [17] 


\subsection{Mechanical testing and characterization}

Fatigue crack propagation behavior of the TDCB specimens was studied by a Shimadzu air servo fatigue and endurance testing system ADTAV02K1S5 (Shimadzu Co., Ltd., Kyoto, Japan) with $2 \mathrm{kN}$ load cell at room temperature $\left(24 \pm 1^{\circ} \mathrm{C}\right)$. The specimens were pre-cracked $(\sim 2.5 \mathrm{~mm})$ with a razor blade while ensuring the pre-crack tip was centered in the groove and immediately cyclically loaded. A triangular waveform of frequency $5 \mathrm{~Hz}$ was applied with a stress ratio, $R$, of $0.1(R=$ $K_{\min } / K_{\max }$, where $K_{\min }$ and $K_{\max }$ denote the minimum and maximum values of the cyclic stress intensity, respectively). Fatigue cracks were grown within constant mode-I stress intensity factor range, $\Delta K_{\mathrm{I}}\left(\Delta K_{\mathrm{I}}=K_{\max }-K_{\min }\right)$. Load line crack opening displacement (COD) was measured by a clip gauge. Mode I fatigue cracks were constrained along the centerline of the specimen because of use of side grooves molded in the specimen (Figure 1). The optically measured crack tip position and specimen compliance were plotted against number of cycles. The linear relationship between optically measured crack length and specimen compliance (Figure 2) was used to calculate the crack tip position of the specimens at all times during the experiment [5]. Each loading condition was investigated with continuous cyclic loading to specimen failure and/or with a rest period to allow for healing with stationary crack faces. In the latter case, cyclic loading was stopped after a small amount of crack growth and healing was allowed under different steadystate stress intensities for different times. In the case of manual infiltration, about $0.5 \mu$ of pre-mixed

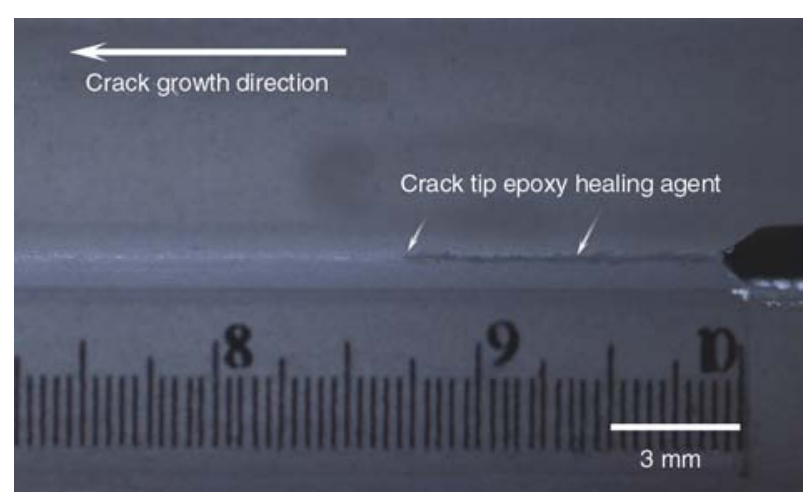

Figure 1. Optical microscopic side view of crack tip during fatigue test of a self-healing specimen. The testing parameters are $\Delta K_{\mathrm{I}}=0.605 \mathrm{MPa} \cdot \mathrm{m}^{1 / 2}, K_{\max }=$ $0.672 \mathrm{MPa} \cdot \mathrm{m}^{1 / 2}, K_{\min }=0.067 \mathrm{MPa} \cdot \mathrm{m}^{1 / 2}, R=0.1$ and $f=5 \mathrm{~Hz}$.

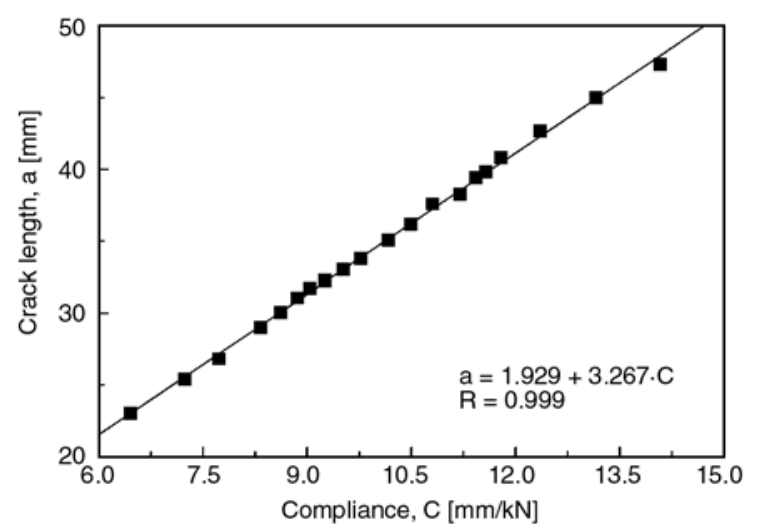

Figure 2. Plot illustrating calculation of continuous cracktip position of self-healing specimen from compliance data and finite optical measurements. The squares (ם) represent compliance values corresponding to the optical data, while the solid line $(-)$ is the linear best fit. The testing parameters are $\Delta K_{\mathrm{I}}=0.605 \mathrm{MPa} \cdot \mathrm{m}^{1 / 2}, K_{\max }=0.672 \mathrm{MPa} \cdot \mathrm{m}^{1 / 2}$, $K_{\min }=0.067 \mathrm{MPa} \cdot \mathrm{m}^{1 / 2}, R=0.1$ and $f=5 \mathrm{~Hz}$.

epoxy and polythiol (keeping the stoichiometric ratio while excluding catalyst) was injected into the crack plane of unfilled epoxy specimen with a microsyringe after a crack growth increment of $\sim 8 \mathrm{~mm}$, and fatigue loading was not interrupted throughout the process [12].

The healing efficiency, $\lambda$, was defined by fatigue life extension [4], see Equation (1):

$\lambda=\frac{N_{\text {Healed }}-N_{\text {Control }}}{N_{\text {Control }}}$

where $N_{\text {Healed }}$ and $N_{\text {Control }}$ denote the total number of cycles to failure of the self-healing specimen and that of a similar control specimen without healing, respectively. For each test, the result was an average of five specimens.

To evaluate original fracture toughness and development of healing efficiency of epoxy specimens, a natural pre-crack $(\sim 2.5 \mathrm{~mm})$ was created on the TDCB specimens by inserting a fresh razor blade and gently tapping into the molded notch starter [15]. Subsequently, the specimen was pin loaded and tested with a Hounsfield 10K-S universal testing machine (Hounsfield Test Equipment Ltd., Surrey, UK) under displacement control using a $3 \mathrm{~mm} / \mathrm{min}$ displacement rate at room temperature. Specimens were fractured only to the end of the groove. For self-healing specimens, they were unloaded and left to cure for different times at room 
temperature. Finally, the healed specimens were tested again following the above procedure.

Micro-Raman measurements were carried out using a Renishaw in Via (Renishaw Co., Ltd., Gloucestershire, UK) spectrometer equipped with a Leica microscope. The Raman spectra were excited by a $785 \mathrm{~nm}$ laser line at a resolution of $1 \mathrm{~cm}^{-1}$, and the laser was focused by a $20 \times$ objective to a spot size of $\sim 1 \mu \mathrm{m}$. Morphological observation and energy dispersive spectroscopy (EDS) analysis were conducted by a Hitachi model S-4800 field emission scanning electron microscope (SEM, manufactured by Hitachi High-Technologies Corporation, Tokyo, Japan). Prior to the experiment, the specimen surface was coated by gold/palladium sputter. Isothermal curing kinetics of the healing agent was studied with a TA differential scanning calorimeter (DSC) Q10 calorimeter (TA Instruments, New Castle, USA) in $\mathrm{N}_{2}$ at $25^{\circ} \mathrm{C}$.

\section{Results and discussion}

\subsection{Self-healing behaviors of the in-situ system}

For successful in-situ self-healing, the healing agent released into the crack plane must have enough time to polymerize [5]. To facilitate the healing process of the cracks soon after their forma-

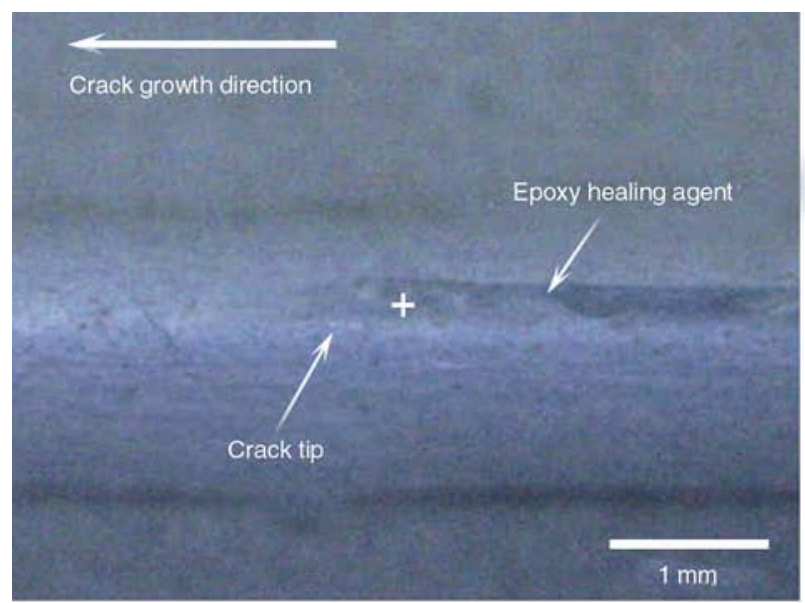

a) tion, fast consolidation of the repair chemicals is required.

As shown in Figure 1, small amount of epoxy healing agent in the vicinity of crack tip is squeezed out during the fatigue crack growth. In-situ confocal Raman microscopy study of this part of healing agent on the self-healing specimen indicates that epoxide groups quickly react with hydrosulfide groups in the presence of catalyst DMP-30 (Figure 3). About $70 \%$ epoxide groups are consumed within $15 \mathrm{~min}$. It means that curing of epoxy healing agent can be completed within very short time.

Accordingly, the development of fracture toughness in self-healing specimens was measured through monotonic fracture tests performed at prescribed times following the initial virgin fracture. It is seen from Figure 4 that after an initial dwell period of about 6 min during which no appreciable healing is measured, the fracture toughness increases rapidly, tapering off after about $30 \mathrm{~min}$. Moreover, time dependence of curing degree of the healing agents measured by differential scanning calorimetry (DSC) shows a similar exponential relationship. The slight difference between the two groups of data should come from (i) mixing uniformity of the healant ingredients under different circumstances, and (ii) the difference in measurement methods [16].

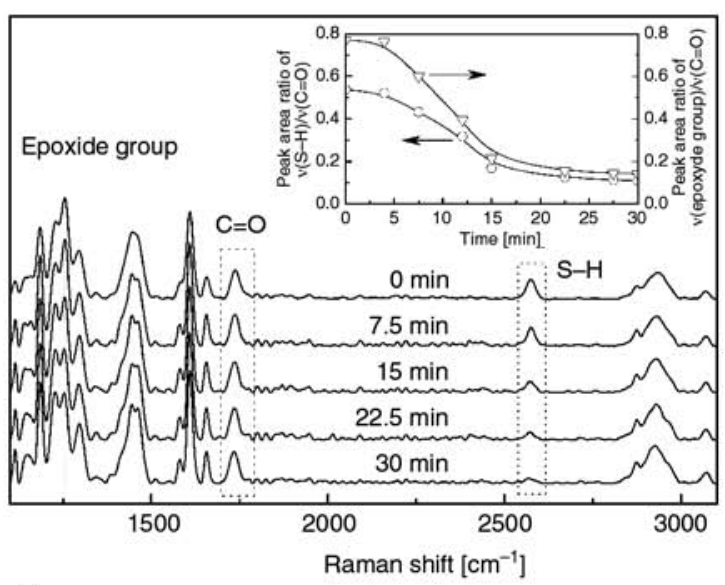

b)

Figure 3. In-situ confocal Raman microscopy observation. The photo (a) displays fatigue crack tip in side groove of a selfhealing specimen. The figure (b) shows typical Raman spectra collected from the center of the extruded healing agent in the vicinity of crack tip at different times counted from crack stop. The inset summarizes time dependences of the characteristic Raman peak area ratios. Here three peaks are of interests: stretching modes of epoxide group at $1256 \mathrm{~cm}^{-1}$, carbonyl group at $1738 \mathrm{~cm}^{-1}$ and hydrosulfide group at $2573 \mathrm{~cm}^{-1}$. Since carbonyl originates from mercaptan, and the reaction between epoxy and mercaptan cannot produce any carbonyl, the peak area of carbonyl group at $1738 \mathrm{~cm}^{-1}$ is able to serve as the reference for evaluating the variation in the peak areas of epoxide and hydrosulfide groups with time. This figure provides a live record of the curing reaction of the released healing agent in an authentic specimen. The testing parameters are $\Delta K_{\mathrm{I}}=0.605 \mathrm{MPa} \cdot \mathrm{m}^{1 / 2}, K_{\max }=$ $0.672 \mathrm{MPa} \cdot \mathrm{m}^{1 / 2}, K_{\min }=0.067 \mathrm{MPa} \cdot \mathrm{m}^{1 / 2}, R=0.1$ and $f=5 \mathrm{~Hz}$. 


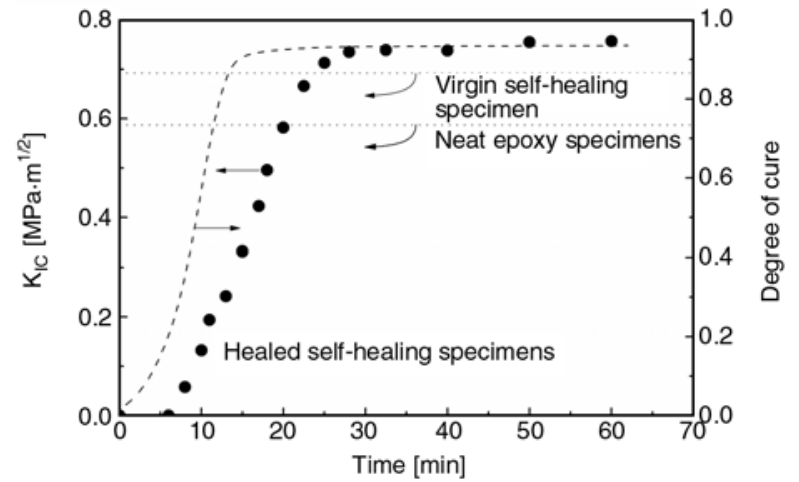

Figure 4. Time dependences of fracture toughness $(\bullet)$ developed in healed self-healing specimen and degree of cure (dash line) of the healing agent. The lower horizontal dotted line represents average $K_{\text {IC }}$ of neat epoxy specimens and the upper horizontal dotted line represents that of virgin self-healing specimens. All the fracture toughness values of self-healing specimens were obtained from monotonic fracture tests. The data of degree of cure were estimated from isothermal polymerization of the healing agent conducted in DSC at $25^{\circ} \mathrm{C}$ [12]. The $K_{\mathrm{IC}}$ of virgin self-healing specimen is higher than that of neat epoxy specimen as a result of toughening effect induced by the embedded microcapsules, which will be discussed in sub-section 3.2 .

On the whole, it can be considered that the increase in fracture toughness keeps in step with degree of cure of the healing agent. The result well agrees with that reported by Brown et al. [5].

Clearly, the above results manifest that healing proceeds quite fast at room temperature, which should satisfy the prerequisite for $i n$-situ repairing fatigue crack.

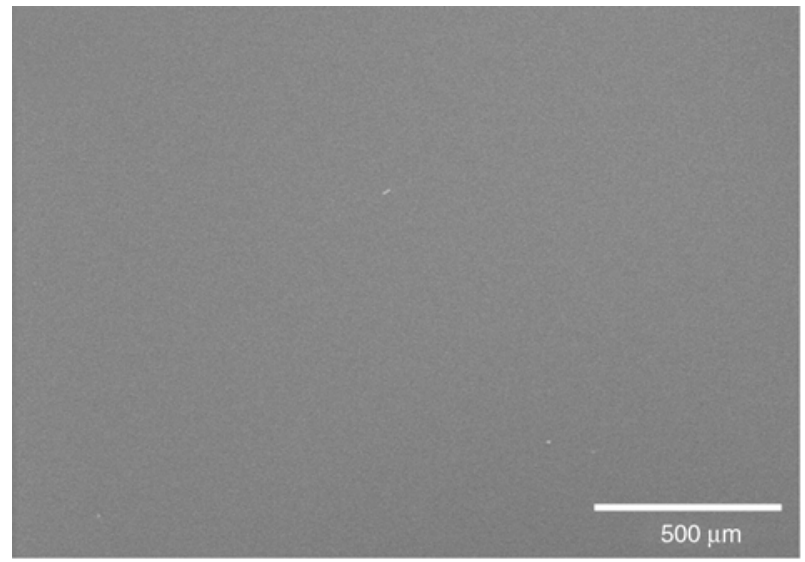

a)

\subsection{Effect of microcapsules on fatigue performance of epoxy}

Incorporation of healing agent capsules into epoxy would certainly affect the latter's properties. As shown in Table 2 and Figure 4, the presence of $20 \mathrm{wt} \%$ microcapsules (i.e. $10 \mathrm{wt} \%$ epoxy-loaded capsules and $10 \mathrm{wt} \%$ polythiol-loaded capsules or hardener-loaded capsules) has raised the virgin monotonic fracture toughness of epoxy by up to $\sim 18 \%$. The toughening effect is also reflected by a change in fracture morphology from mirror-like of the unfilled epoxy to hackle markings of the capsules filled version (Figure 5). The result coincides with previous report on a similar system, where crack pinning mechanism was believed to take the responsibility $[13,14,17]$. Such an increase of material's toughness would inevitably improve its fatigue performance because of the increased resistance to fatigue crack propagation.

Additionally, under cyclic loading condition, the forces required to squeeze the fluidic healing agent (released from the broken capsules) out of the crack during unloading and to draw the fluid into the crack during loading would shield the crack tip [18]. This hydrodynamic pressure crack tip shielding mechanism can also improve the resistance to fatigue crack propagation. Here in this work, the effect is firstly revealed by manually injecting the mixture of epoxy prepolymer and polythiol at the stoichiometric ratio of 1.2:1 by weight (which is the same as the healing agent formulation except that the amine catalyst is excluded) into the crack plane of neat epoxy specimen without interrupting the

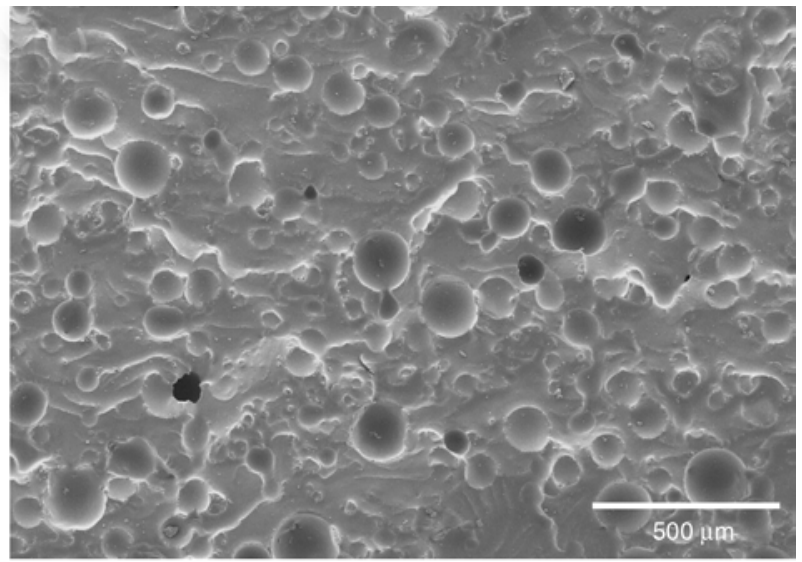

b)

Figure 5. SEM micrographs of fatigue fracture surfaces of (a) neat epoxy specimen and (b) control specimen. The testing parameters are $\Delta K_{\mathrm{I}}=0.504 \mathrm{MPa} \cdot \mathrm{m}^{1 / 2}, K_{\max }=0.560 \mathrm{MPa} \cdot \mathrm{m}^{1 / 2}, K_{\min }=0.056 \mathrm{MPa} \cdot \mathrm{m}^{1 / 2}, R=0.1$ and $f=5 \mathrm{~Hz}$. Note: The crack propagates from left to right in the images. 


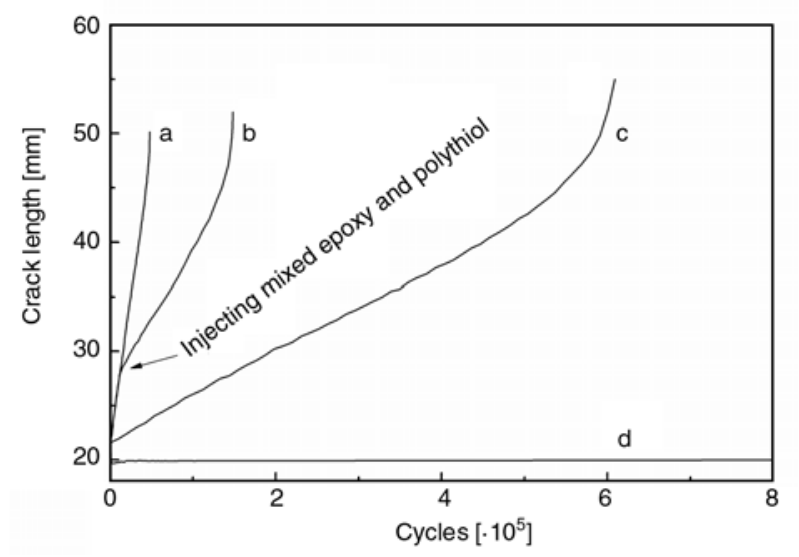

Figure 6. Crack length vs. fatigue cycle of (a) neat epoxy specimen, (b) manual infiltration specimen, (c) control specimen and (d) self-healing specimen. The manual injection specimen was injected by the stoichiometric mixture of epoxy and polythiol excluding the amine catalyst in dynamic infiltration fashion [12]. The testing parameters are $\Delta K_{\mathrm{I}}=0.504 \mathrm{MPa} \cdot \mathrm{m}^{1 / 2}, K_{\max }=0.560 \mathrm{MPa} \cdot \mathrm{m}^{1 / 2}$, $K_{\min }=0.056 \mathrm{MPa} \cdot \mathrm{m}^{1 / 2}, R=0.1$ and $f=5 \mathrm{~Hz}$.

fatigue experiment (Figure 6). The infiltrated liquid mixture can be considered to be chemically stable because epoxy-polythiol would hardly react with each other without proper catalysis. As a result, the subsequent crack propagation keeps steadiness on the whole like the case of submerged specimens [19]. Compared to the neat epoxy specimen, the infiltration greatly decreases the crack growth rate from $1.8 \cdot 10^{-3} \mathrm{~mm} /$ cycle to $4.0 \cdot 10^{-4} \mathrm{~mm} /$ cycle and increases the fatigue life by $\sim 207 \%$ (cf. curves a and $b$ in Figure 6 ). The results agree with those observed in the case of infiltration of epoxy prepolymer (or the hardener, i.e. mixture of PMP and DMP-30) alone [12]. Secondly, the dependence of crack length on fatigue cycle of control specimen with $10 \mathrm{wt} \%$ epoxy-loaded capsules and $10 \mathrm{wt} \%$ polythiol-loaded capsules (no tertiary amine catalyst is included) was measured (curve $\mathrm{c}$ in Figure 6). The crack growth rate is further reduced to $1.3 \cdot 10^{-4} \mathrm{~mm} /$ cycle, and the fatigue life extension increases by $\sim 1161 \%$ comparing with neat epoxy specimen. It means that both microcapsules induced-toughening and hydrodynamic pressure crack tip shielding mechanisms have taken effect, while the former makes more contribution to retardation of fatigue crack than the latter.

When the healing agent flowing out of the broken microcapsules contain catalyst and could rapidly react, polymeric wedge and adhesive bonding mechanisms [12-14] are involved, which can greatly extend fatigue life of the material (see curve d in Figure 6). More details of this aspect will be discussed in the next section.

\subsection{Effect of applied range of cyclic stress intensity}

Following the traditional crack closure concept [18, 20-26], it is known that if fatigue crack opening load is purposely increased at the crack tip of selfhealing specimens by the aforesaid four mechanisms (i.e. microcapsules induced-toughening, hydrodynamic pressure crack tip shielding, polymeric wedge and adhesive bonding), the effective stress intensity factor range, $\Delta K_{\text {eff, would be }}$ reduced accordingly, see Equation (2):

$$
\begin{aligned}
\Delta K_{\text {eff }} & =\Delta K_{\mathrm{I}}-\Delta K_{\text {toughening }}-\Delta K_{\text {liquid }}- \\
& -\Delta K_{\text {bonding }}-\Delta K_{\text {wedge }}
\end{aligned}
$$

where $\Delta K_{\text {toughening denotes the stress intensity due to }}$ microcapsules induced increase of matrix ductility, $\Delta K_{\text {liquid }}$ the crack-opening and crack-closure stress intensity from viscosity resistance of the liquid, $\Delta K_{\text {bonding }}$ the stress intensity due to the combined (tensile) stresses in adhesives across the crack faces, and $\Delta K_{\text {wedge }}$ the crack-closure stress intensity due to the wedge from adhesives gelling and hardening.

Considering that the competition between polymerization kinetics and crack growth would be a major factor affecting successful healing, three levels of applied range of stress intensity were prescribed for the fatigue tests of self-healing specimens hereinafter: two high cycle fatigue cases and one low cycle fatigue case. The high cycle fatigue refers to the fatigue regime of low $\Delta K_{\mathrm{I}}$, relatively slow crack growth rate and longer fatigue life (even infinite life). Low cycle fatigue refers to the fatigue regime where $K_{\max }$ approaches $K_{\mathrm{IC}}$ and rapid crack growth causes specimen failure after very short time.

For low $\Delta K_{\mathrm{I}}$, chemical kinetics of the healing agent dominates, the crack is fully arrested within short time, and self-healing provides infinite fatigue life extension. In this regime, the specimen's fatigue life exceeds the time for the healing agent to gel and for quasi-static healing efficiency to develop [5]. For example, when $\Delta K_{\mathrm{I}}=0.504 \mathrm{MPa} \cdot \mathrm{m}^{1 / 2}$ $\left(K_{\max } / K_{\mathrm{IC}}=0.81\right)$, self-healing specimens were precracked and immediately cyclically loaded. A typi- 
cal plot of crack length vs. fatigue cycle is shown by curve $d$ in Figure 6 . The initial release of healing agent during precracking firstly retards the crack growth, and leads to certain amount of crack regression $(\sim 2 \mathrm{~mm})$. After a few cycles, the crack does not further progress within the time frame of the test ( $10^{7}$ cycles) and hence is fully arrested. According to Equation (1), the healing efficiency is infinite. This behavior was repeatedly observed for all the five specimens tested. In contrast, the precrack in the control specimen is more rapidly growing at a constant rate (see curve c in Figure 6).

When the self-healing specimen with fully arrested fatigue crack was fractured under static load without precrack, its fracture toughness was found to be $0.963 \mathrm{MPa} \cdot \mathrm{m}^{1 / 2}$, which is much higher than that of virgin self-healing specimen $\left(0.695 \mathrm{MPa} \cdot \mathrm{m}^{1 / 2}\right)$. As shown in Figure 7, the healing agent released during the precrack event has formed a partial polymer wedge at the crack tip. Cohesive failure of the cured healing agent is confirmed by micro-Raman and energy dispersive spectroscopy (EDS) analysis (figure omitted). Obviously uniform tearing traces appear on the fast fracture plane when the healing agent is in the rubbery state (Figure 7b). It implies that stronger adhesion effect is obtained at lower $\Delta K_{\mathrm{I}}$, which favors to arrest fatigue crack. Therefore, adhesive bonding and polymeric wedge shielding mechanisms play an important role to indefinitely extend fatigue life of the material in this regime.

With a further rise in $\Delta K_{\mathrm{I}}$, crack growth rate has to be greatly reduced but the crack cannot be fully arrested. In this regime, the self-healing specimen's

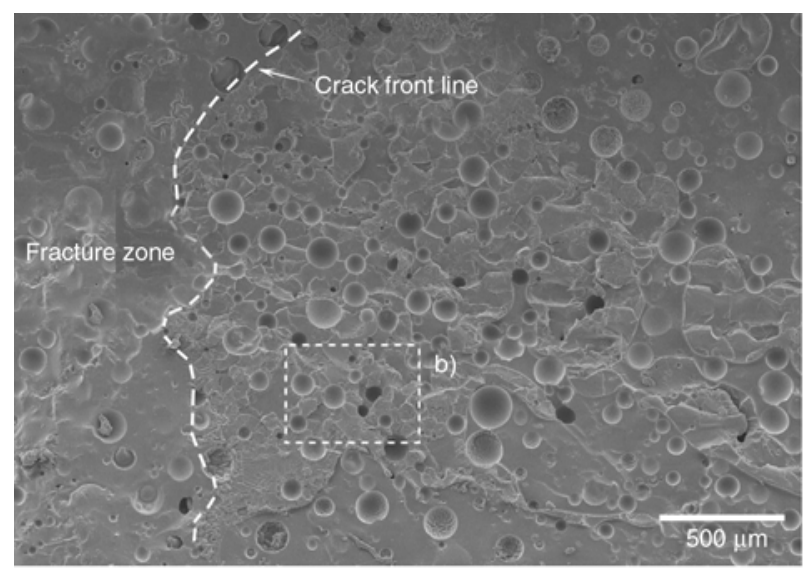

a)

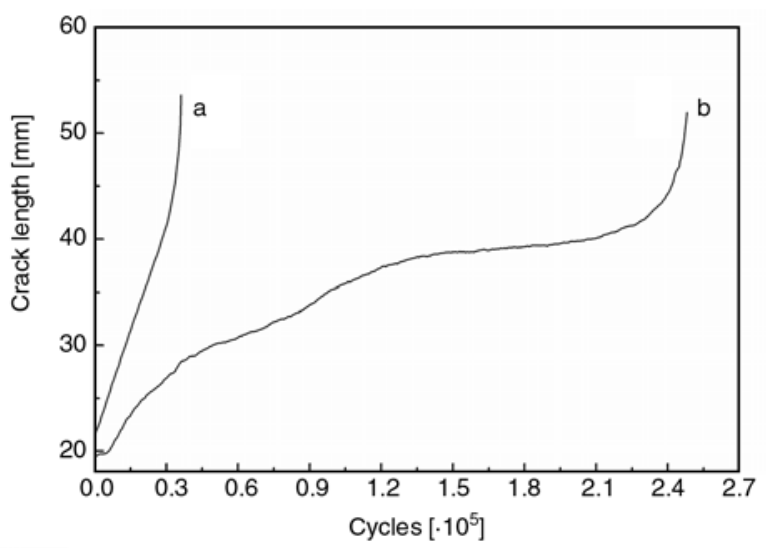

Figure 8. Crack length vs. fatigue cycles of (a) control specimen and (b) self-healing specimen. The testing parameters are $\Delta K_{\mathrm{I}}=0.554 \mathrm{MPa} \cdot \mathrm{m}^{1 / 2}, K_{\max }=$ $0.616 \mathrm{MPa} \cdot \mathrm{m}^{1 / 2}, K_{\min }=0.062 \mathrm{MPa} \cdot \mathrm{m}^{1 / 2}, R=0.1$ and $f=5 \mathrm{~Hz}$.

fatigue life approaches the time for the healing agent to gel. For example, when $\Delta K_{\mathrm{I}}=$ $0.504 \mathrm{MPa} \cdot \mathrm{m}^{1 / 2}\left(K_{\max } / K_{\mathrm{IC}}=0.89\right)$, the crack growth is retarded at the beginning (refer to curve b in Figure 8) in a way similar to curve $d$ in Figure 6. Following this period of crack arrest, the crack eventually grows past the healed precrack at $\sim 6 \cdot 10^{4}$ cycles. The subsequent crack growth behavior is a combination of steady growth and retardation, offering a healing efficiency of about $575 \%$. In the course of fatigue crack propagation, as shown in Figure 9, large quantities of epoxy healing agent were squeezed into thin cakes densely covering the fatigue fracture surface, and some were extruded into tiny balls filling in the concaves left by the broken microcapsules. Besides cohesive failure of the

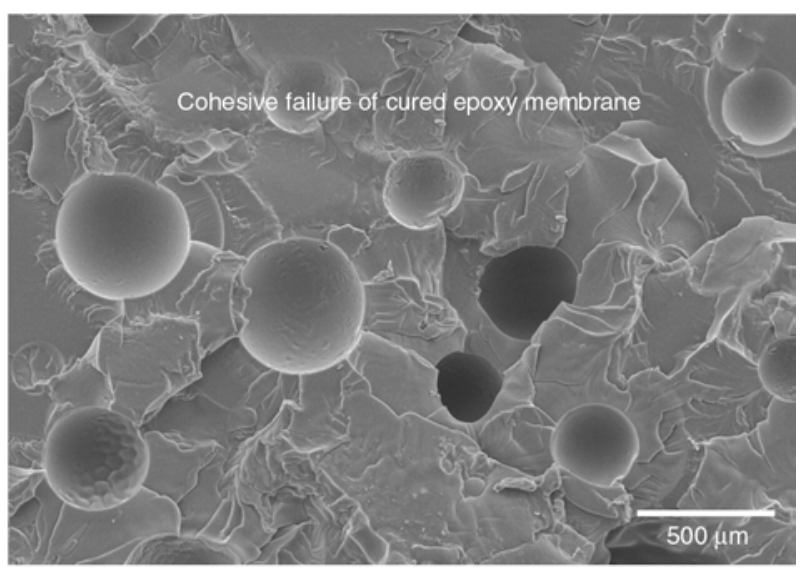

b)

Figure 7. SEM micrographs of fatigue fracture surface of self-healing specimen. Crack can hardly advance for $1 \cdot 10^{7}$ cycles and hence is fully arrested. The specimen was fractured under static load using a rate of displacement of $3 \mathrm{~mm} / \mathrm{min}$ without precrack. The fatigue testing parameters are $\Delta K_{\mathrm{I}}=0.504 \mathrm{MPa} \cdot \mathrm{m}^{1 / 2}, K_{\max }=0.560 \mathrm{MPa} \cdot \mathrm{m}^{1 / 2}$, $K_{\min }=0.056 \mathrm{MPa} \cdot \mathrm{m}^{1 / 2}, R=0.1$ and $f=5 \mathrm{~Hz}$. Note: The crack propagates from right to left in the images. 


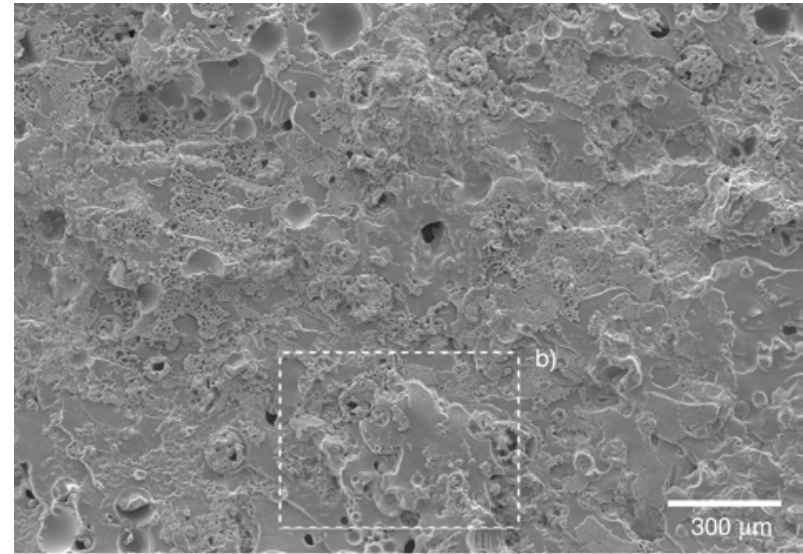

a)

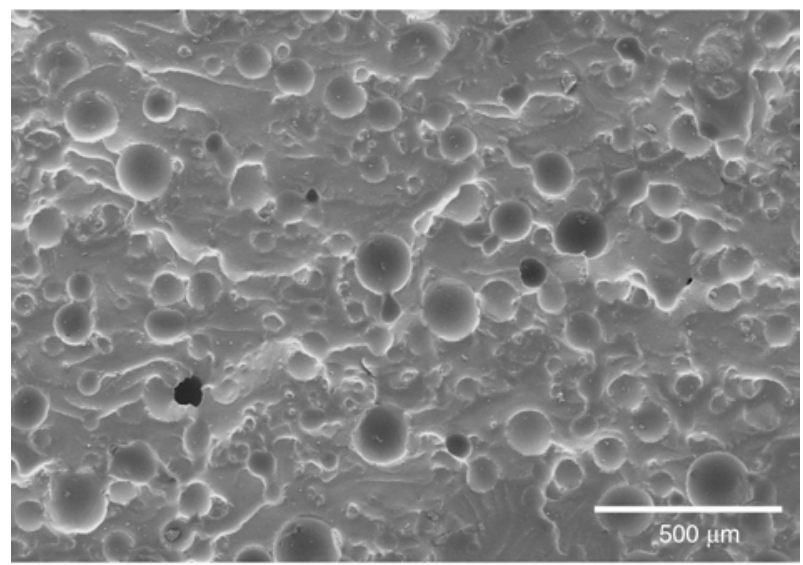

b)

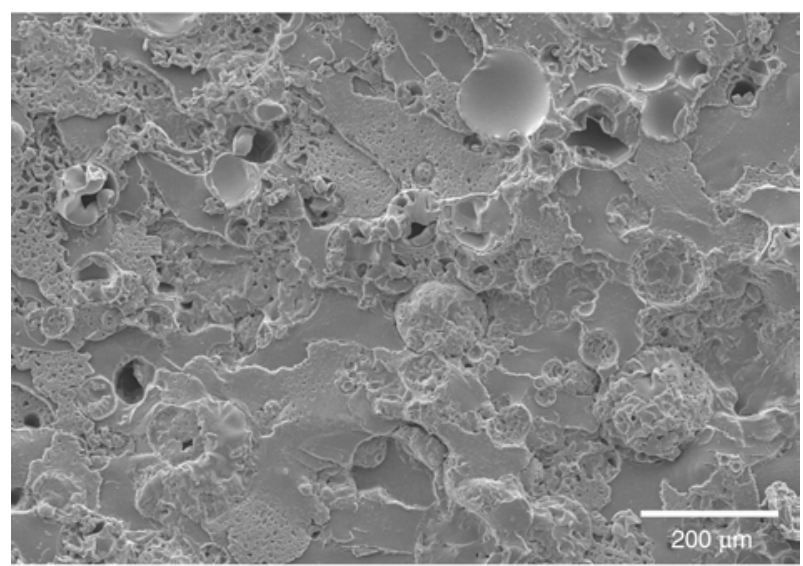

c)

Figure 9. SEM micrographs of fatigue fracture surface of self-healing specimen. The testing parameters are $\Delta K_{\mathrm{I}}=0.554 \mathrm{MPa} \cdot \mathrm{m}^{1 / 2}, K_{\max }=0.616 \mathrm{MPa} \cdot \mathrm{m}^{1 / 2}$, $K_{\min }=0.062 \mathrm{MPa} \cdot \mathrm{m}^{1 / 2}, R=0.1$ and $f=5 \mathrm{~Hz}$. Note: The crack propagates from left to right in the images.

cured healing agent membranes, adhesively bonded epoxy from the opposite fracture plane is also discovered at some regions. Both result in retardation of crack growth (Figure 8). Evidently, adhesive bonding mechanism governs fatigue life extension in this regime.

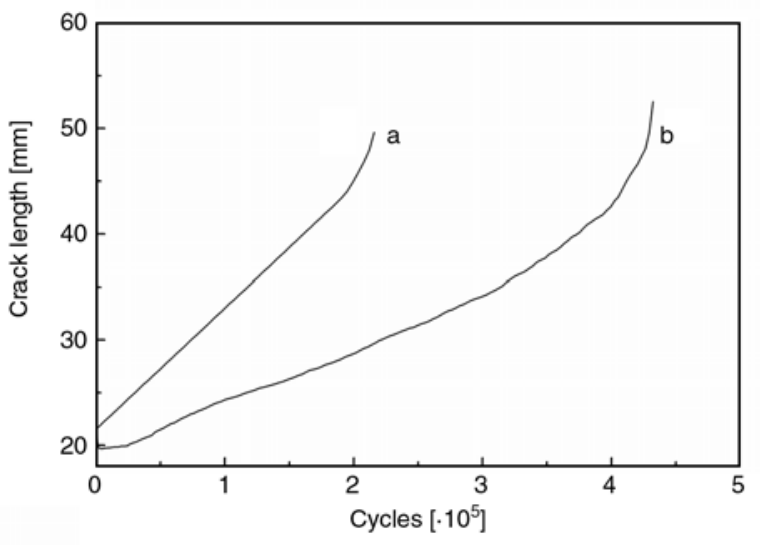

Figure 10. Crack length vs. fatigue cycles of (a) control specimen and (b) self-healing specimen. The testing parameters are $\Delta K_{\mathrm{I}}=0.605 \mathrm{MPa} \cdot \mathrm{m}^{1 / 2}$, $K_{\max }=0.672 \mathrm{MPa} \cdot \mathrm{m}^{1 / 2}, K_{\min }=0.067 \mathrm{MPa} \cdot \mathrm{m}^{1 / 2}$, $R=0.1$ and $f=5 \mathrm{~Hz}$.

Under high $\Delta K_{\mathrm{I}}$ (i.e. when $K_{\max }$ approaches $K_{\mathrm{IC}}$ ), the mechanical kinetics of fatigue crack growth is extremely fast and the healing system does not have sufficient time to inhibit the crack propagation. This causes specimen failure within very short time. In this regime, the specimen fatigue life lags behind the time for the healing agent to gel. For example, when $\Delta K_{\mathrm{I}}=0.605 \mathrm{MPa} \cdot \mathrm{m}^{1 / 2}\left(K_{\max } / K_{\mathrm{IC}}=0.97\right)$, the fatigue crack in the self-healing specimen shows a constant growth rate with occasional crack retardation (refer to curve $b$ in Figure 10). The healing efficiency is estimated to be about $89 \%$. Accordingly, the SEM photos in Figure 11 indicate that the released healing agent has sparsely covered the fatigue fracture surface, and some were stretched into tapeworm-shaped gels with obvious tearing traces. It suggests that the healing agent suffered from severe tension action in the process of gelling or polymerization. On the basis of these results, we know that when the mechanical kinetics of fatigue crack growth becomes the controlling factor, the liberated healing agent lacks enough time to produce strong adhesion for inhibiting the crack advance.

It is worth noting that, when $\Delta K_{\mathrm{I}}$ further increases, as $K_{\max }$ overly approaches the fracture toughness of the polymer, $K_{\text {IC }}$, unstable fracture will occur. A summary of life extension values under different loading conditions is given in Figure 12. The lower the applied range of stress intensity, the more evident the retardation effect and the higher healing efficiency. This trend is fully in line with the simu- 


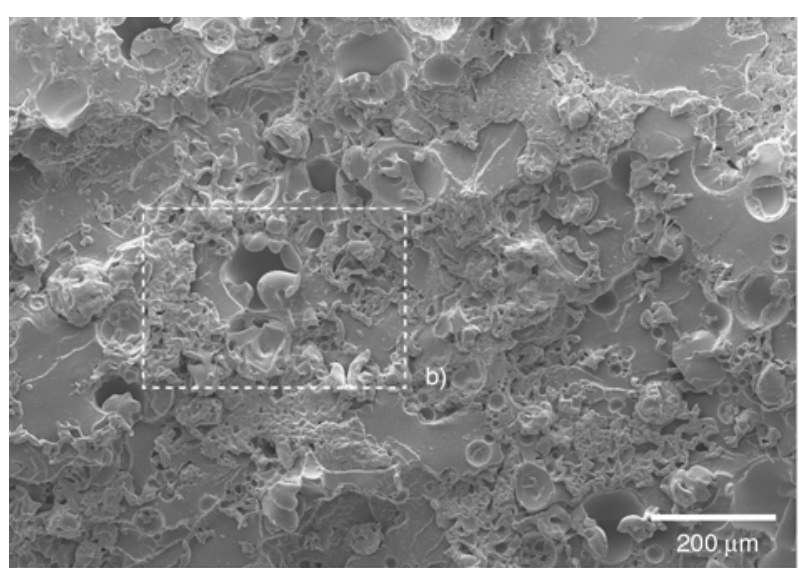

a)

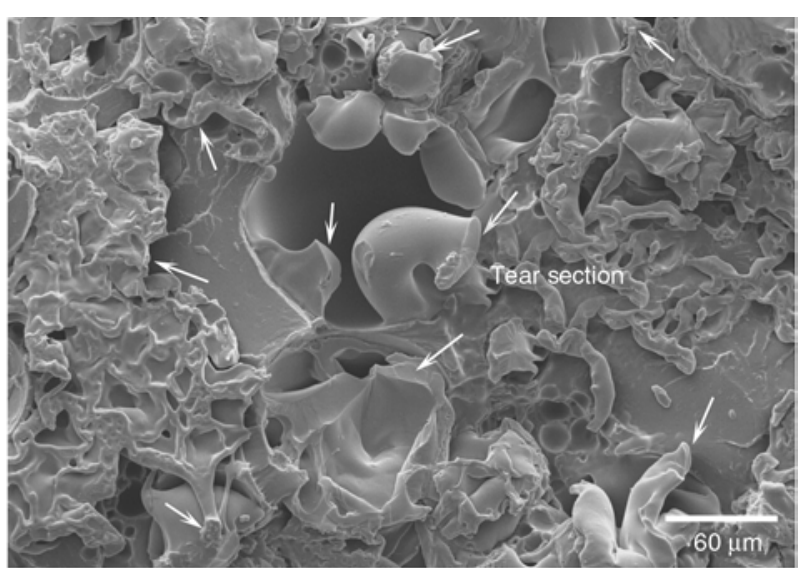

b)

Figure 11. SEM micrographs of fatigue fracture surface of self-healing specimen. The testing parameters are $\Delta K_{\mathrm{I}}=$ $0.605 \mathrm{MPa} \cdot \mathrm{m}^{1 / 2}, K_{\max }=0.672 \mathrm{MPa} \cdot \mathrm{m}^{1 / 2}, K_{\min }=0.067 \mathrm{MPa} \cdot \mathrm{m}^{1 / 2}, R=0.1$ and $f=5 \mathrm{~Hz}$. Note: The crack propagates from left to right in the images.

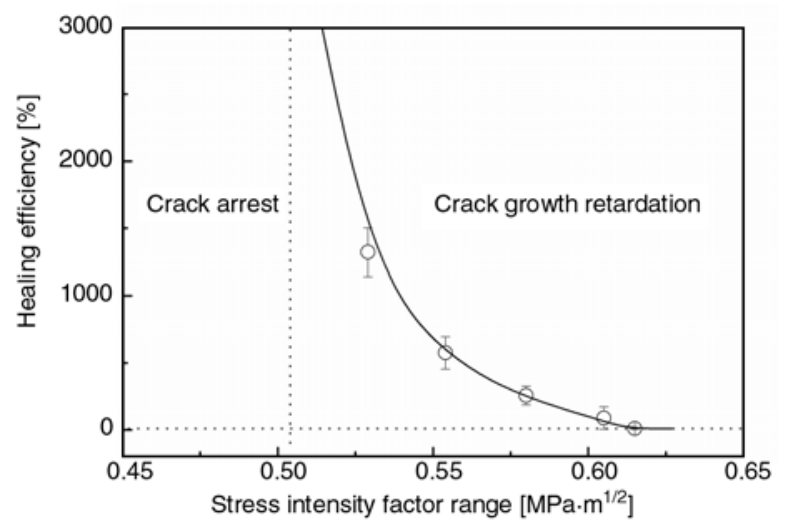

Figure 12. Healing efficiency of self-healing specimens as a function of stress intensity factor range, $\Delta K_{\mathrm{I}}$. The data are calculated partly using the results in Figure 6, 8 and 10.

lative healing results by dynamic manual infiltration [12]. Especially when $\Delta K_{\text {I }}$ is not more than $0.504 \mathrm{MPa} \cdot \mathrm{m}^{1 / 2}$, crack can hardly advance for more than $10^{7}$ cycles as a result of gelation and solidification of the healing agent, and hence is considered to be fully arrested. In this context, the value of $\Delta K_{\mathrm{I}}$ of $0.504 \mathrm{MPa} \cdot \mathrm{m}^{1 / 2}$ represents a watershed between fatigue crack growth retardation and crack arrest. Compared with control specimen, the mechanisms of adhesive bonding and polymeric wedge involved in crack tip shielding of self-healing specimens are highlighted, regardless whether $\Delta K_{\text {I }}$ is high or low.

\subsection{Effects of steady-state stress intensity and healing time}

According to Equation (2), it is known that if the fatigue crack opening load is purposely increased by a wedge with adhesive properties at the crack tip, the effective stress intensity factor range would be reduced [18, 20-26]. Keeping this idea in mind, researchers have made attempts to artificially introduce crack surface contact. Size and performance of the wedge have been found to be the most crucial factors affecting the crack closure effect. In this work, loading condition is investigated with a rest period to allow that (i) healing can be conducted with stationary crack faces and (ii) the healing agent flowing out of the capsules can form a crosslinked epoxy wedge in the crack tip. Meantime, the wedge size is adjusted by changing the steady-state stress intensity required for holding the crack open after a small amount of crack growth, while the wedge performance is tuned by changing the steady-state healing time, during which the cyclic loading pauses and crack is held open.

Figure 13 exhibits that the fatigue life extension due to precrack healing is drastically improved by adding a rest period. In the case of steady-state stress intensity $=0$, loading is stopped after a small amount of crack growth and the specimen is allowed to heal unloaded for $10 \mathrm{~min}$ to ensure partial cure of the healing agent. The crack tip regresses to the approximate position of the TDCB notch as shown by curve $b$ in Figure 13. Then, after about $4.1 \cdot 10^{4}$ cycles, the crack tip slowly progresses through the healed region to its location prior to healing. The crack growth rate of the selfhealing specimens is lower than that of control specimens on the whole because the fracture toughness of the healing agent develops rapidly within 


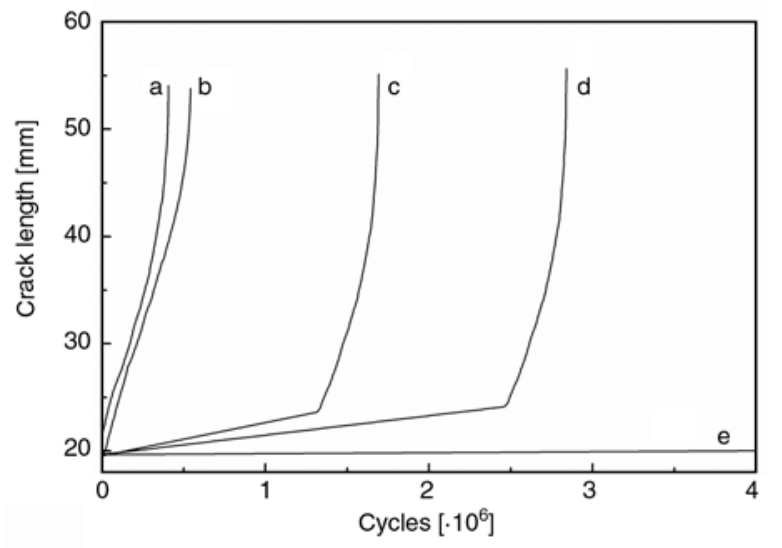

Figure 13. Crack length vs. fatigue cycles of self-healing specimens. The applied steady-state stress intensity for holding crack open and steady-state healing time are: (a) $0 \mathrm{MPa} \cdot \mathrm{m}^{1 / 2}, 0 \mathrm{~min}$, (b) $0 \mathrm{MPa} \cdot \mathrm{m}^{1 / 2}, 10 \mathrm{~min}$, (c) $0.336 \mathrm{MPa} \cdot \mathrm{m}^{1 / 2}$, $9.5 \mathrm{~min}$, (d) $0.168 \mathrm{MPa} \cdot \mathrm{m}^{1 / 2}, \quad 10 \mathrm{~min}$, and (e) $0.336 \mathrm{MPa} \cdot \mathrm{m}^{1 / 2}, 10 \mathrm{~min}$. The testing parameters are $\Delta K_{\mathrm{I}}=0.605 \mathrm{MPa} \cdot \mathrm{m}^{1 / 2}, \quad K_{\max }=$ $0.672 \mathrm{MPa} \cdot \mathrm{m}^{1 / 2}, K_{\min }=0.067 \mathrm{MPa} \cdot \mathrm{m}^{1 / 2}, R=$ 0.1 and $f=5 \mathrm{~Hz}$.

short period of time and exceeds that of matrix as indicated in Figure 4. The fatigue healing efficiency for this case is around $33 \%$.

Sharp et al. [18] indicated that the load level or stress intensity applied for holding the crack open plays a decisive role in retarding or arresting fatigue crack. Evidently, it is also valid for the current system. Fatigue crack growth is retarded at different steady-state stress intensities. Higher steady-state stress intensity applied during healing results in

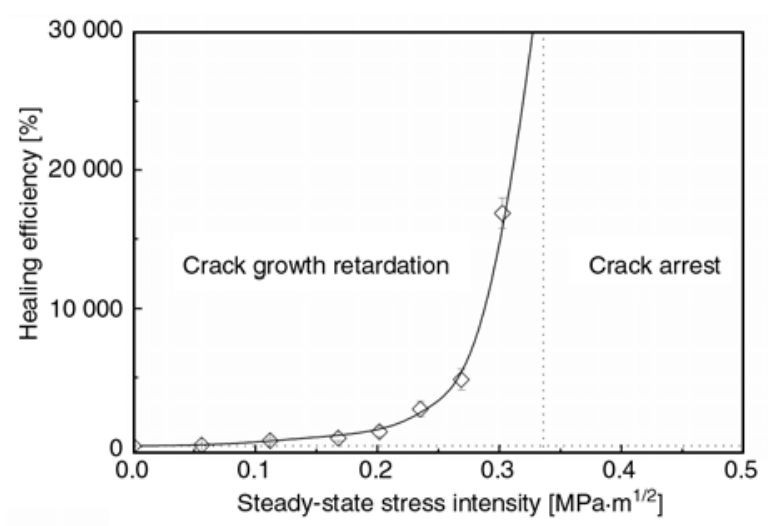

Figure 14. Healing efficiency of self-healing specimens with a rest period as a function of the applied steady-state stress intensity. The data are calculated partly using the results in Figure 13. The steady-state healing time is set at $10 \mathrm{~min}$. The testing parameters are $\Delta K_{\mathrm{I}}=0.605 \mathrm{MPa} \cdot \mathrm{m}^{1 / 2}$, $K_{\max }=0.672 \mathrm{MPa} \cdot \mathrm{m}^{1 / 2}, K_{\min }=0.067 \mathrm{MPa} \cdot \mathrm{m}^{1 / 2}$, $R=0.1$ and $f=5 \mathrm{~Hz}$. more prominent retardation effect (Figure 13) and higher healing efficiency (Figure 14). The results coincide with those obtained by the simulative healing through static manual infiltration [12]. When the applied stress intensity is not less than $0.336 \mathrm{MPa} \cdot \mathrm{m}^{1 / 2}$ (for the steady-state healing time of $10 \mathrm{~min}$ ), crack can hardly advance for more than $10^{7}$ cycles and is considered to be completely arrested. Therefore, the applied stress intensity of $0.336 \mathrm{MPa} \cdot \mathrm{m}^{1 / 2}$ acts as a threshold for distinguishing fatigue crack growth retardation from crack arrest (Figure 14). The above results can be understood by the fact that thicker wedge is produced when the specimen is healed at higher applied steady-state stress intensity. Consequently, $\Delta K_{\text {wedge }}$ increases and $\Delta K_{\text {eff }}$ decreases (refer to Equation (2)). When $\Delta K_{\text {eff }} \leq \Delta K_{\text {th }}$ (i.e. $\Delta K_{\text {bonding }}+$ $\Delta K_{\text {wedge }} \geq \Delta K_{\mathrm{I}}-\Delta K_{\mathrm{th}}$ ), fatigue crack is fully arrested.

Taking the specimen with fatigue crack arrested at steady-state stress intensity of $0.336 \mathrm{MPa} \cdot \mathrm{m}^{1 / 2}$ as an example. The specimen is eventually fractured at static load without precrack and the fracture toughness reaches $1.089 \mathrm{MPa} \cdot \mathrm{m}^{1 / 2}$, much higher than the value of the virgin self-healing specimen $\left(0.695 \mathrm{MPa} \cdot \mathrm{m}^{1 / 2}\right)$. As shown in Figure 15, the healing agent released during the precrack event has formed a thick polymer wedge at the crack tip, leading to cohesive failure of the matrix in the ultimate fracture experiment. Very strong adhesion must have been achieved, which certainly favors to arrest crack.

In addition to the above study on the effect of steady-state stress intensity that is related to wedge size, the influence of steady-state healing time that is related to wedge performance is evaluated in the following. For this purpose, the fatigue test paused after a small amount of crack growth and the crack was held open at a constant steady-state stress intensity of $0.336 \mathrm{MPa} \cdot \mathrm{m}^{1 / 2}$. After different steadystate healing times from 0 to $1 \mathrm{~h}$, fatigue loading was reestablished.

The results shown in Figure 13 and 16 indicate that the healing effect is negligible (healing efficiency $=$ $10 \sim 15 \%$ ) within the steady-state healing time range of $0 \sim 8.5 \mathrm{~min}$. When the steady-state healing time reaches 9.5 and $9.75 \mathrm{~min}$, however, the healing efficiency is greatly increased to 415 and $1263 \%$, respectively. In the case that the steady-state heal- 


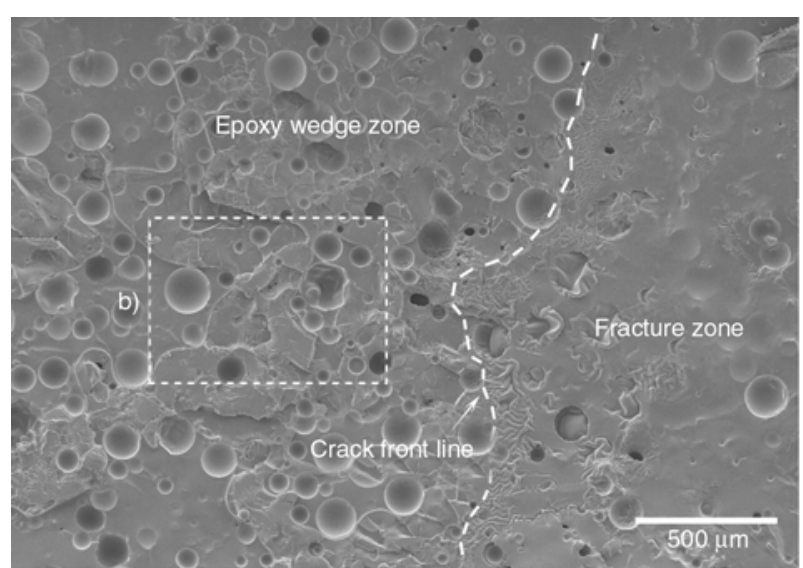

a)

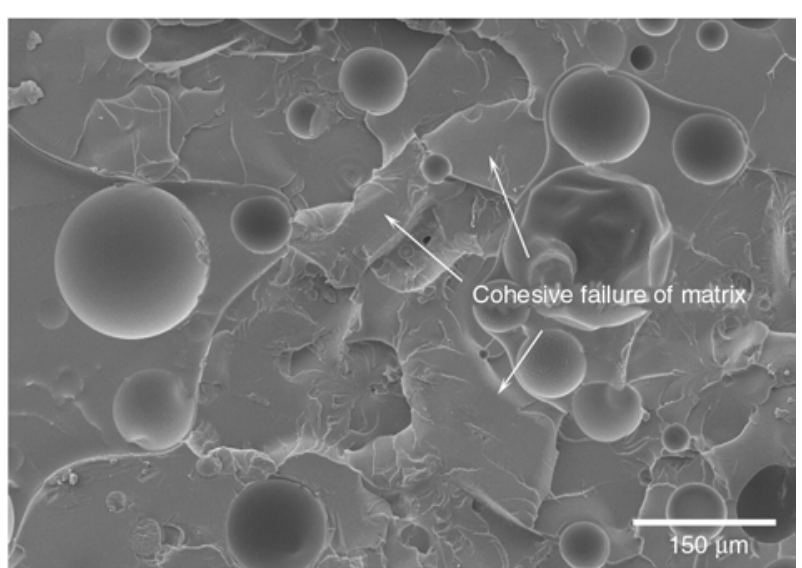

b)

Figure 15. SEM micrographs of fatigue fracture surface of self-healing specimen. The applied steady-state stress intensity for holding crack open is $0.336 \mathrm{MPa} \cdot \mathrm{m}^{1 / 2}$ and the steady-state healing time is $10 \mathrm{~min}$. Crack can hardly advance for 107 cycles and hence is fully arrested. The specimen was fractured under static load using a rate of displacement of $3 \mathrm{~mm} / \mathrm{min}$ without precrack. The fatigue testing parameters are $\Delta K_{\mathrm{I}}=0.605 \mathrm{MPa} \cdot \mathrm{m}^{1 / 2}, K_{\max }=$ $0.672 \mathrm{MPa} \cdot \mathrm{m}^{1 / 2}, K_{\min }=0.067 \mathrm{MPa} \cdot \mathrm{m}^{1 / 2}, R=0.1$ and $f=5 \mathrm{~Hz}$. Note: The crack propagates from left to right in the images.

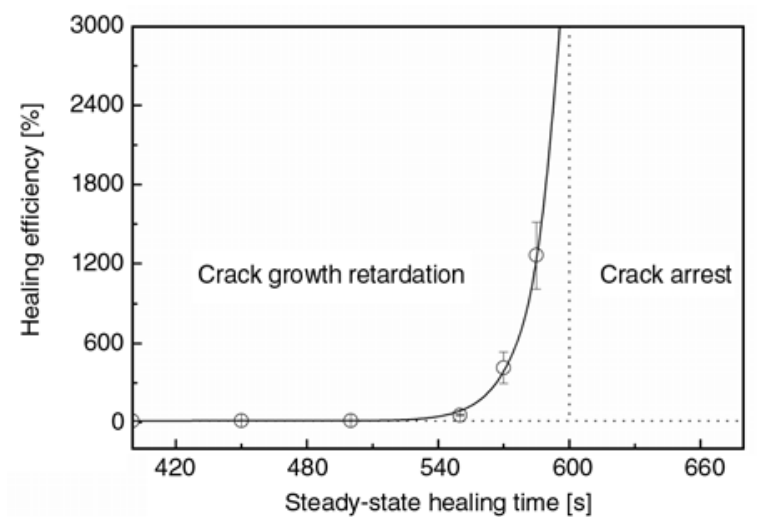

Figure 16. Healing efficiency of self-healing specimens with a rest period as a function of steady-state healing time. The data are calculated partly using the results in Figure 13. The applied steadystate stress intensity for holding crack open is $0.336 \mathrm{MPa} \cdot \mathrm{m}^{1 / 2}$. The testing parameters are $\Delta K_{\mathrm{I}}=0.605 \mathrm{MPa} \cdot \mathrm{m}^{1 / 2}, K_{\max }=0.672 \mathrm{MPa} \cdot \mathrm{m}^{1 / 2}$, $K_{\min }=0.067 \mathrm{MPa} \cdot \mathrm{m}^{1 / 2}, R=0.1$ and $f=5 \mathrm{~Hz}$.

ing time is not less than 10 min, crack can hardly advance after more than $10^{7}$ fatigue cycles and is considered to be fully arrested. Similarly, this time can be regarded as the critical threshold to distinguish fatigue crack growth retardation from crack arrest (Figure 16). The phenomena have been found in the simulative healing tests based on static manual infiltration [12], but the critical value of steadystate healing time becomes longer for the present in-situ system. It might be because the ingredients ratio, mixing uniformity and amount of the released healing agent in fatigue crack of self-healing speci- mens are not optimized as the case of simulative healing $[12,14]$.

The above results are closely related to the curing process of the healing agent and the development of its fracture toughness. During curing of the healing agent, the system transforms from low molecular liquid mixture into three dimensionally cross-linked macromolecular networks. Molecular dynamics and macroscopic behavior of the material drastically change in the meantime [16]. Previous study on curing kinetics demonstrated that the viscosity of the healing agent slowly increased in the beginning a few minutes after mixing, and then rapidly increased until it gelled within about one minute $[13,14]$. The gelation of the healing agent is essentially a rapid formation and increase process of hardness and adhesive strength as shown in Figure 4. Although nearly no adhesion can be detected at a time less than $6 \mathrm{~min}$, fracture toughness of the healing agent sharply increases as of $8 \mathrm{~min}$, and exceeds that of the epoxy matrix at about 20 min. With the rapid development of bonding strength of the cured healing agent, fatigue crack growth would become gradually difficult in the starting position. The deduction is confirmed by the fact that the longer the steady-state healing time corresponds to the fewer tearing marks in the gel state appearing at the initial phase of the fatigue crack (figure omitted). Accordingly, evident retardation effect is obtained for the steady-state healing time from 8 to 
9.75 min and the crack is fully arrested for the steady-state healing time as of $10 \mathrm{~min}$.

\section{Conclusions}

The self-healing epoxy materials containing encapsulated epoxy/mercaptan system exhibit significantly extended fatigue life as compared with the unfilled versions. Effects of microcapsules inducedtoughening, hydrodynamic pressure crack tip shielding, polymeric wedge and adhesive bonding account for the improvement. Under different operation circumstances, however, the above mechanisms exert different influences on crack retardation.

The healing efficiency strongly depends on the applied stress intensity range, $\Delta K_{\mathrm{I}}$. The lower $\Delta K_{\mathrm{I}}$, the higher healing efficiency. The applied stress intensity range of $0.504 \mathrm{MPa} \cdot \mathrm{m}^{1 / 2}$ represents a watershed between fatigue crack growth retardation and crack arrest for the current system.

In the case of high $\Delta K_{\mathrm{I}}$, extension of fatigue life in self-healing specimens can also be achieved by holding the crack open for a while after a small amount of crack growth. Higher steady-state stress intensity required for holding the crack open results in more prominent retardation effect. When the steady-state stress intensity is not less than $0.336 \mathrm{MPa} \cdot \mathrm{m}^{1 / 2}$ (for the steady-state healing time of $10 \mathrm{~min}$ ), crack can hardly advance for more than $10^{7}$ cycles and is considered to be completely arrested. In this case, adhesive bonding and polymeric wedge mechanisms play the controlling role. Similarly, on the other hand, when the steady-state healing time is not less than $10 \mathrm{~min}$ (for the steadystate stress intensity of $\left.0.336 \mathrm{MPa} \cdot \mathrm{m}^{1 / 2}\right)$, the fatigue crack is fully arrested.

\section{Acknowledgements}

The authors are grateful to the support of the Natural Science Foundation of China (Grants: U0634001, 20874117, 50573093, 51073176 and 50903095), Doctor Fund of Ministry of Education of China (Grant: 2009310004111671) and the Science and Technology Program of Guangdong Province (Grant: 2010B010800021) and China Postdoctoral Science Foundation.

\section{References}

[1] Murphy E. B., Wudl F.: The world of smart healable materials. Progress in Polymer Science, 35, 223-251 (2010).

DOI: 10.1016/j.progpolymsci.2009.10.006
[2] Yuan Y. C., Yin T., Rong M. Z., Zhang M. Q.: Self healing in polymers and polymer composites. Concepts, realization and outlook: A review. Express Polymer Letters, 2, 238-250 (2008).

DOI: $10.3144 /$ expresspolymlett.2008.29

[3] Caruso M. M., Davis D. A., Shen Q., Odom S. A., Sottos N. R., White S. R., Moore J. S.: Mechanicallyinduced chemical changes in polymeric materials. Chemical Reviews, 109, 5755-5798 (2009).

DOI: $10.1021 / \mathrm{cr} 9001353$

[4] Brown E. N., White S. R., Sottos N. R.: Retardation and repair of fatigue cracks in a microcapsule toughened epoxy composite - Part I: Manual infiltration. Composites Science and Technology, 65, 2466-2473 (2005).

DOI: $10.1016 /$ j.compscitech.2005.04.020

[5] Brown E. N., White S. R., Sottos N. R.: Retardation and repair of fatigue cracks in a microcapsule toughened epoxy composite - Part II: In situ self-healing. Composites Science and Technology, 65, 2474-2480 (2005).

DOI: 10.1016/j.compscitech.2005.04.053

[6] Jones A. S., Rule J. D., Moore J. S., Sottos N. R., White S. R.: Life extension of self-healing polymers with rapidly growing fatigue cracks. Journal of the Royal Society Interface, 4, 395-403 (2007).

DOI: 10.1098/rsif.2006.0199

[7] Maiti S., Geubelle P. H.: Cohesive modeling of fatigue crack retardation in polymers: Crack closure effect. Engineering Fracture Mechanics, 73, 22-41 (2006). DOI: $10.1016 /$ j.engfracmech.2005.07.005

[8] Maiti S., Shankar C., Geubelle P. H.: Continuum and molecular-level modeling of fatigue crack retardation in self-healing polymers. Journal of Engineering Materials and Technology-Transactions of the ASME, 128, 595-602 (2006).

DOI: $10.1115 / 1.2345452$

[9] White S. R., Sottos N. R., Geubelle P. H., Moore J. S., Kessler M. R., Sriram S. R., Brown E. N., Viswanathan S.: Autonomic healing of polymer composites. Nature, 409, 794-797 (2001). DOI: $10.1038 / 35057232$

[10] Daniel J. S., Kim Y. R.: Laboratory evaluation of fatigue damage and healing of asphalt mixtures. Journal of Materials in Civil Engineering, 13, 434-440 (2001).

DOI: 10.1061/(ASCE)0899-1561(2001)13:6(434)

[11] Zako M., Takano N.: Intelligent material systems using epoxy particles to repair microcracks and delamination damage in GFRP. Journal of Intelligent Material Systems and Structures, 10, 836-841 (1999). DOI: 10.1106/YEIH-QUDH-FC7W-4QFM

[12] Yuan Y. C., Rong M. Z., Zhang M. Q., Yang G. C., Zhao J. Q.: Healing of fatigue crack in epoxy materials with epoxy/mercaptan system via manual infiltration. Express Polymer Letters, 4, 644-658 (2010). DOI: $10.3144 /$ expresspolymlett.2010.79 
[13] Yuan Y. C., Rong M. Z., Zhang M. Q., Chen J., Yang G. C., Li X. M.: Self-healing polymeric materials using epoxy/mercaptan as the healant. Macromolecules, 41, 5197-5202 (2008).

DOI: $10.1021 / \mathrm{ma} 800028 \mathrm{~d}$

[14] Yuan Y. C., Rong M. Z., Zhang M. Q., Yang G. C.: Study of factors related to performance improvement of self-healing epoxy based on dual encapsulated healant. Polymer, 50, 5771-5781 (2009).

DOI: $10.1016 /$ j.polymer.2009.10.019

[15] Brown E. N., Sottos N. R., White S. R.: Fracture testing of a self-healing polymer composite. Experimental Mechanics, 42, 372-379 (2002).

DOI: $10.1007 / \mathrm{BF} 02412141$

[16] Petrie E. M.: Epoxy adhesive formulations. McGrawHill, New York (2006).

[17] Brown E. N., White S. R., Sottos N. R.: Fatigue crack propagation in microcapsule-toughened epoxy. Journal of Materials Science, 41, 6266-6273 (2006).

DOI: $10.1007 / \mathrm{s} 10853-006-0512-y$

[18] Sharp P. K., Clayton J. Q., Clark G.: Retardation and repair of fatigue cracks by adhesive infiltration. Fatigue and Fracture Engineering Materials and Structures, 20, 605-614 (1997).

DOI: 10.1111/j.1460-2695.1997.tb00292.x

[19] Elber W.: Fatigue crack closure under cyclic tension. Engineering Fracture Mechanics, 2, 37-45 (1970). DOI: $10.1016 / 0013-7944(70) 90028-7$
[20] James M. N., Smith G. C.: Surface microcrack closure in fatigue: A comparison of compliance and crack sectioning data. International Journal of Fracture, 22, R69-R75 (1983).

DOI: $10.1007 / \mathrm{BF} 00942729$

[21] Song P. S., Hwang S., Shin C. S.: Effect of artificial closure materials on crack growth retardation. Engineering Fracture Mechanics, 60, 47-58 (1998). DOI: 10.1016/S0013-7944(97)00180-X

[22] Shin C. S., Cai C. Q.: Surface fatigue crack growth suppression in cylindrical rods by artificial infiltration. International Journal of Fatigue, 30, 560-567 (2008). DOI: $10.1016 /$ j.ijfatigue.2007.03.005

[23] Shin C. S., Wang C. M., Song P. S.: Fatigue damage repair: A comparison of some possible methods. International Journal of Fatigue, 18, 535-546 (1996). DOI: $10.1016 / \mathrm{S} 0142-1123(96) 00029-1$

[24] Ur-Rehman A., Thomason P. F.: The effect of artificial fatigue crack closure on fatigue crack growth. Fatigue and Fracture of Engineering Materials and Structures, 16, 1081-1090 (1993).

DOI: $10.1111 / \mathrm{j} .1460-2695.1993 . t b 00079 . x$

[25] Shin C. S., Chen Z. Z.: Fatigue life extension by electroless nickel infiltration plating. International Journal of Fatigue, 23, 777-788 (2001).

DOI: 10.1016/S0142-1123(01)00038-X

[26] Wang Y., Zho M., Feng D.: A study of retarding fatigue crack growth using an artificial wedge. Fatigue and Fracture of Engineering Materials and Structures, 16, 363-376 (1993). DOI: $10.1111 / \mathrm{j} .1460-2695.1993 . t b 00093 . x$ 